\title{
Long-term Deformation Measurements of Atypical Roof Timber Structures
}

\author{
Jiří Bureš, Otakar Švábenský, Marek Kalina \\ Brno University of Technology, Faculty of Civil Engineering, Veveři 331/95, 60200 Brno, \\ Czech Republic, E-mail: bures.j@fce.vutbr.cz, svabensky.o@fce.vutbr.cz, \\ kalina.m@fce.vutbr.cz
}

\begin{abstract}
The paper includes conclusions from evaluation of results obtained from long-term measuring of innovative atypical roof timber structures. Based on the results of measurements of vertical and horizontal deformation components it is possible to analyze the real behavior of structures in given conditions. By assessing deformations in various stages, including particularly external and internal environment temperatures, relative air humidity and moisture content of wood, decisive parameters for real structure behavior can be established. The data are processed from period $2001-2013$.
\end{abstract}

Key words: geodetic deformation measurement, atypical roof timber constructions

\section{Introduction}

Timber is a traditional natural material from which a roof structures are built, characterized by strength, low weight and good workability. Wooden structures further have an aesthetic appearance, and therefore the market is still very much in demand of them.
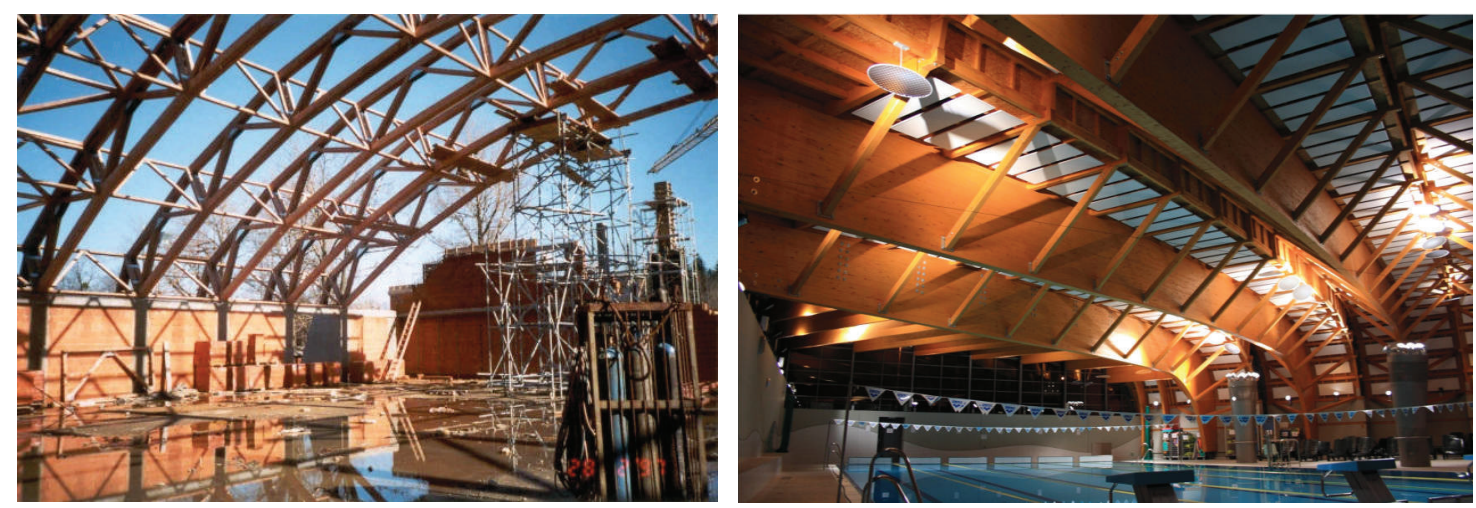

Figure 1: Tennis hall in Frýdlant nad Figure 2: Swimming pool in Brno, 2010, span Ostravicí, 1997, span 40,4 m

$35 \mathrm{~m}$

Today, the building industry increasingly use wood or wood-based materials mostly in roofing of smaller objects but more frequent is the use of wood in the construction of large span structures of complex geometric shapes [1]. This trend will most likely continue which is proved by the number of structures built in the Czech Republic and especially abroad. In Figure 1 is a sample of the roof structure in the tennis hall of Frýdlant nad Ostravicí, made from solid wood and put into operation in 1997 (span 40,4 m). In Figure 2 is a sample of the roof structure of swimming pool in Brno, made of glued solid beams with span of $35 \mathrm{~m}$, placed in service in 2010 [2]. Usage of new technologies raises the need for the design feedback in the form of monitoring during construction and after commissioning to verify their actual behavior in given conditions, while this information is used to refine the static models and to optimize the material design of new 
structures of a similar nature. To monitor effectively the actual performance of roof structures the geodetic measuring methods are used [3], [4].

Technical regulations for construction and operation of buildings require partially the systematic measurement of displacements and deformations. The influence of environment leads to gradual changes in the mutual spatial relationship of different parts of structures (sinking and creep), which is reflected in measurable distortions of geometric parameters. It is purposeful to measure regularly these deformation phenomena in appropriate intervals (measurement epochs). The following text presents the results of long-term measurement of large span roof of the multipurpose sports hall in Bílovec monitored since 2001.

\section{Basic Information about the Measured Structure}

Sporty multi-purpose hall in Bílovec was implemented in 2001. Figure 3 gives a view of the completed structure inside the hall. Hall ground is rectangular measuring $60 \times 30 \mathrm{~m}$. The main structure supporting the roof system is made up from three-hinged arches with a span of $59 \mathrm{~m}$ (Figure 4).

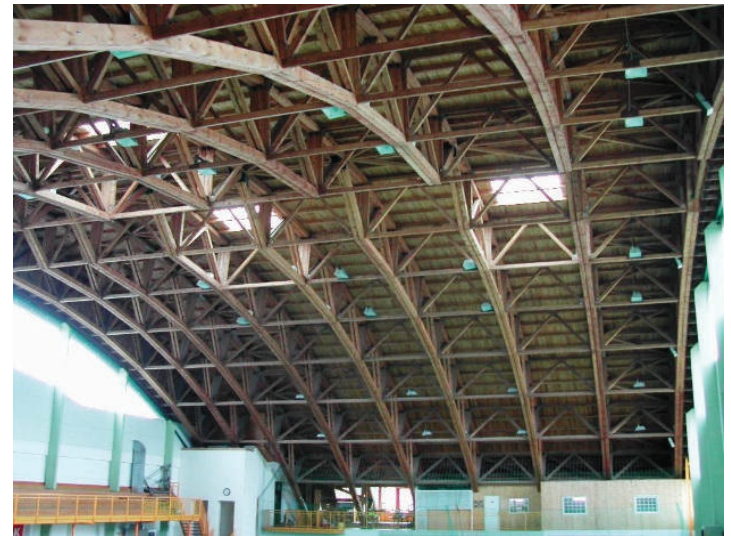

Figure 3: Roof after its completion

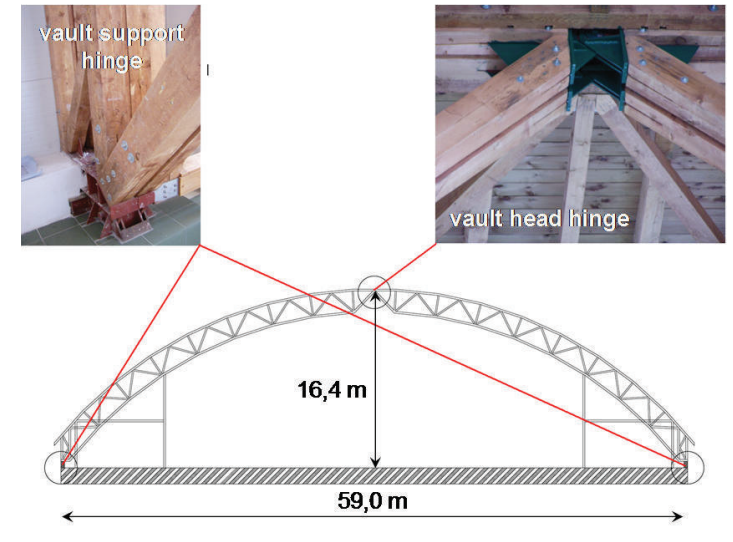

Figure 4: Three-hinged arch

The arches are in the transverse direction stiffened by longitudinal and lateral bracing, and the entire framework creates the spatial carrying system [4]. Bar connections in the joints are designed using thin steel plates inserted in the slots and steel nails [5]. The roof structure supporting is attached to the concrete foundation footings by hinge bearings. Installation of the roof structure was realized with high accuracy (actual radial deviation of the roundness of the structure did not exceed $16 \mathrm{~mm}$ ) [4].

After completion of the structure the geometric parameters of the construction are changing gradually due to touch down and creeping of the various components in joints. Other important factors affecting the deformation are weather conditions, especially the effects of temperature and humidity, and seasonal influences. Due to insolation the roof deck is warming which is reflected by expansion effects. In winter, the hall is from outside exposed to frost and snow load. Inside the temperature is maintained by the air conditioning on $+15^{\circ} \mathrm{C}$. The roof structure of the hall is systematically geodetically monitored since its commissioning in 2001. For the period 20012013, data are available from 8 epochs of measurement in different seasons.

\section{Measuring System and Measurement Technology}

The behavior of the observed roof structure is evaluated on base of measurement results of surveying markers system mounted on the lower bands of arch construction. The entire structure is composed of nine arches, measuring markers are mounted on five of them. Site network consists 
of 36 surveying markers, their positioning in the section and plan is shown in Figure 5. The control system consists of 4 surveying marks 9011-9014 set up on the supporting pillars of the structure side walls. Surveying marks are in the shape of $30 \mathrm{~mm}$ targets with concentric circles.

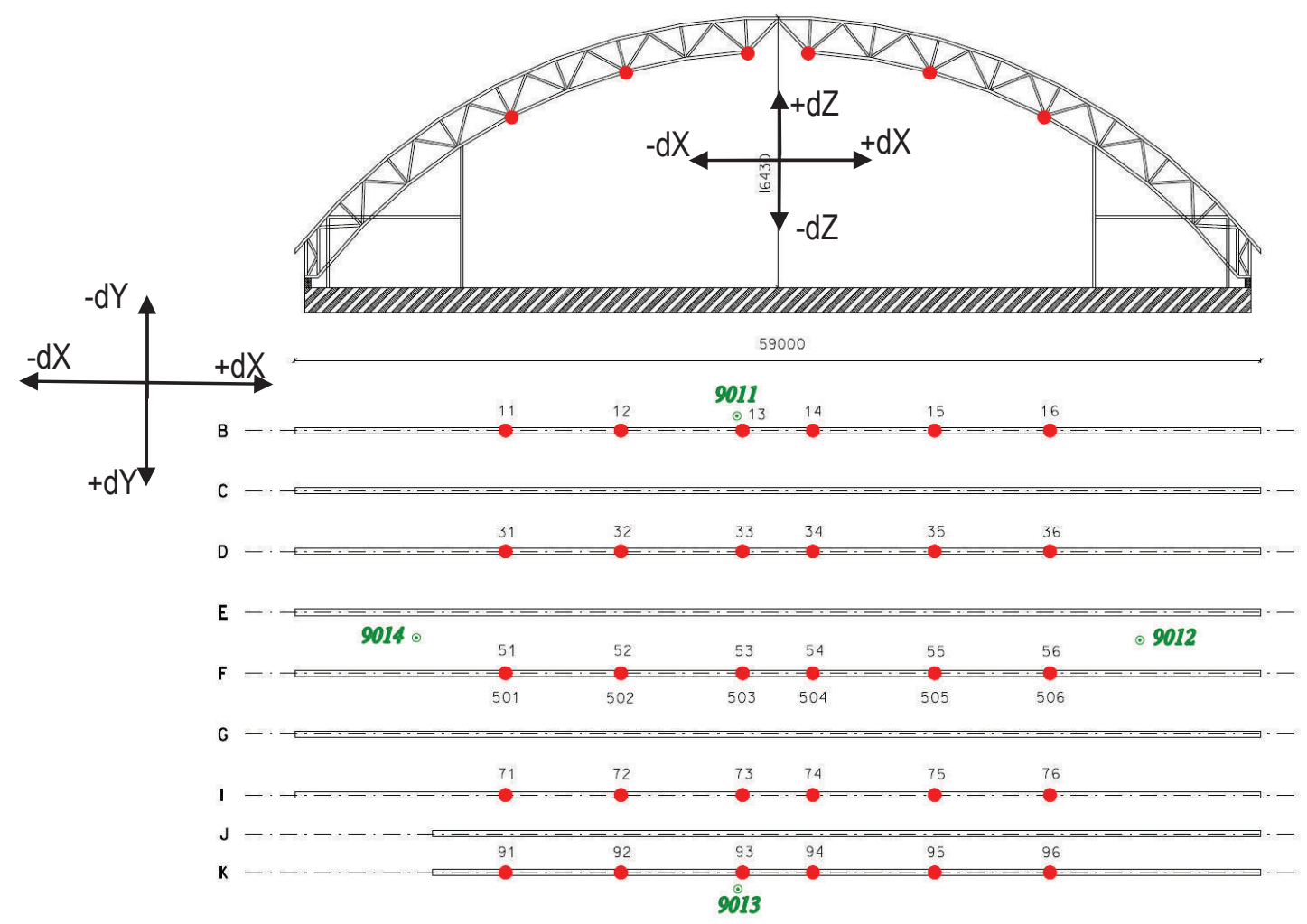

Figure 5: Layout of the construction surveying markers

The measurement technology is based on the method of the spatial intersection of the angles measured by total station with an angular accuracy of $0.5 \mathrm{mgon}$ from four free stations configured as quadrangle points geodetic positions in the transitional form stabilized during surveys by geodetic tripods. During the measurements the values of air temperature, surface temperature structure and relative humidity are recorded by data loggers Comet.

From the data in each stage the spatial coordinates are calculated using least squares adjustment (LSA). Cartesian coordinate system $\mathrm{X}, \mathrm{Y}, \mathrm{Z}$ is oriented in the direction of main axes of the construction (Figure 5). From the differences of the coordinates in various epochs the deformations can be evaluated in the longitudinal, transverse and vertical direction. Characteristics of the accuracy of coordinates derived from the LSA can be directly used to calculate the uncertainties in deformations and their interpretation. An analysis of the accuracy of the single measurement epochs, the mean expanded uncertainty for an epoch deformation is $\Delta \delta=$ $1.4 \mathrm{~mm}$ ( for $\mathrm{K}=2, \mathrm{P}=0.95, \alpha=5 \%$ ).

\section{Results of Evolution of Deformations}

In Figure 6 is shown in plan in form of isolines and color hypsometry the state of longitudinal deformation, in Figure 7 the state of transverse imperfections. In terms of distribution of the longitudinal strain it is evident that half the roof structure is deformed more strongly than the other, due to the structural arrangement of trusses which is different in both halves of the structure. 
Maximum longitudinal deformations are as high as $7 \mathrm{~mm}$, and maximum values of transverse imperfections are up to $8 \mathrm{~mm}$, while the isolines with support of color hypsometry can help to identify the most-stressed particular structural components joints.

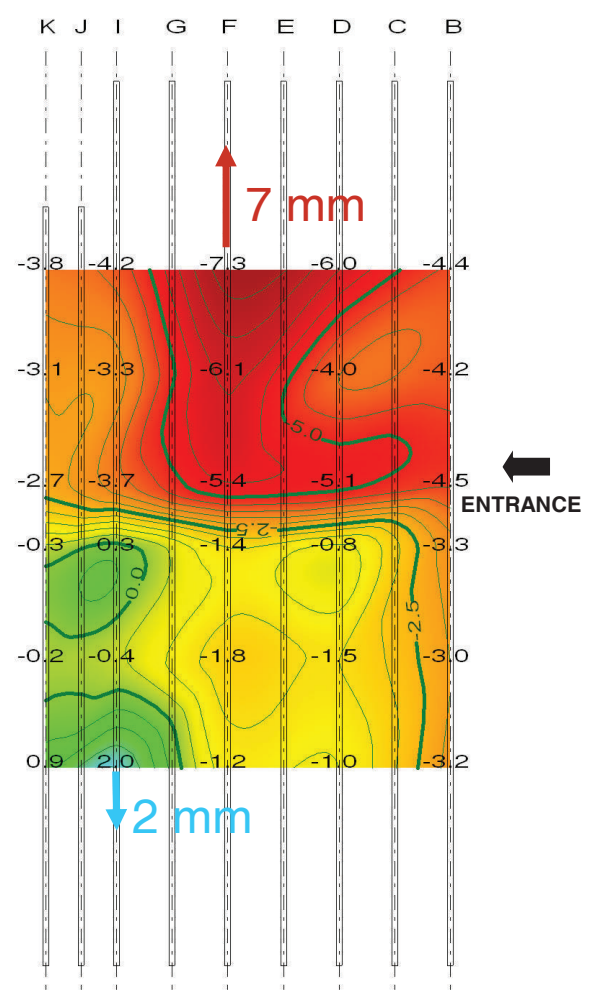

Figure 6: Longitudinal deformation

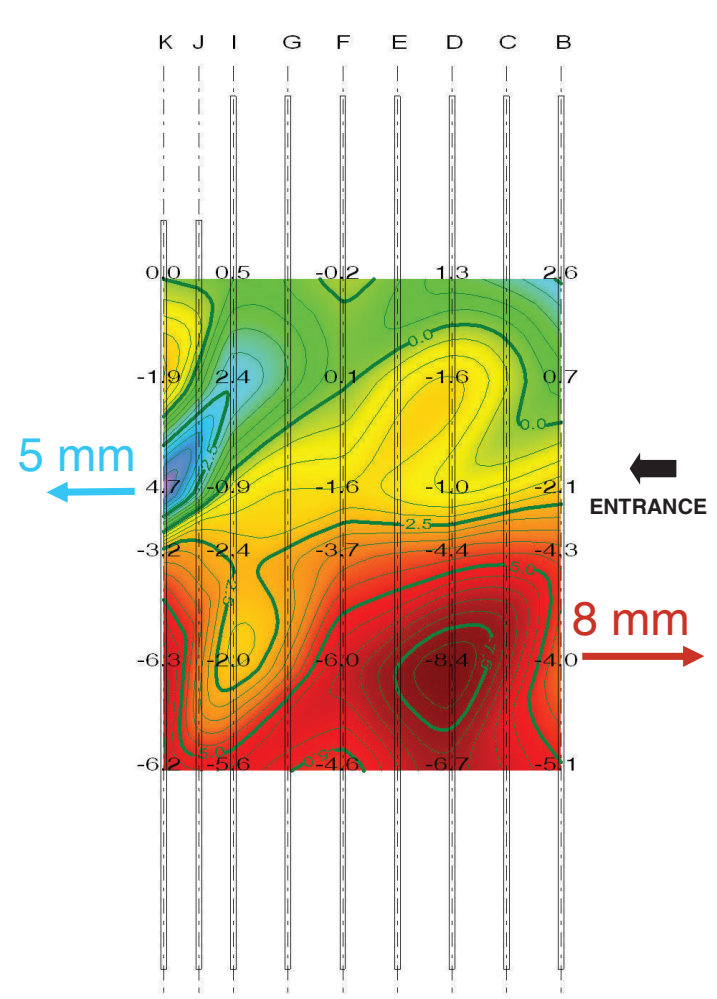

Figure 7: Transverse imperfections

In Figure 8 the state of vertical deformations of the roof structure after 12 years of its commissioning. In vertical direction of the monitored roof construction the greatest distortions were in the tops of arches, considerably smaller vertical deformations were in arch quarters. Over the years, the hall vertical deformations gradually slightly increased. The values of deformation are strongly influenced by exposure to ambient temperature. In winter there is a vertical downward movement - the deflection of the roof, and in the summer months there is a vertical shift upwards [6], [7]. The vertical deformations are manifested mostly by decrease amounting to $18 \mathrm{~mm}$ at the top of the arch, and shrinking toward the arch 1/4., where are smaller than $5 \mathrm{~mm}$. Deformations are partially compensated by movements in the underlying spherical bearings and in the top hinge. Mechanics of motion of the arch construction is in a section shown in Figure 9. Figure 10 shows the evolution of the vertical deformation at the top of the arc in time given in calendar months from the beginning of the surveying, and the temperature in intermediate epochs of measurement. At higher temperatures in summer there is an uplift in the top of the arc, and vice versa at low temperatures in winter is the top to decrease. In particular, the vertical deformation are strongly influenced by ambient temperature. The effect of temperature shows in the vertical change of about $4 \mathrm{~mm}$ over $10^{\circ} \mathrm{C}$ temperature changes.

Figure 11 shows the evolution of the vertical deformation at the top of the arc in time given in calendar months from the beginning of the surveying with correcting temperature influence in intermediate epochs of measurement. It is evident from the development of vertical deformation that during approximately the first 15 months after the commissioning proceeded the gradual fitting together with the creeping yield of the construction joints. 
After one or two years the construction has settled, what was demonstrated by permanent vertical deformation at arc top $16,4 \mathrm{~mm}$, and after 10 years of commissioning the vertical deformations have not changed within accuracy limits and therefore the construction is stable.

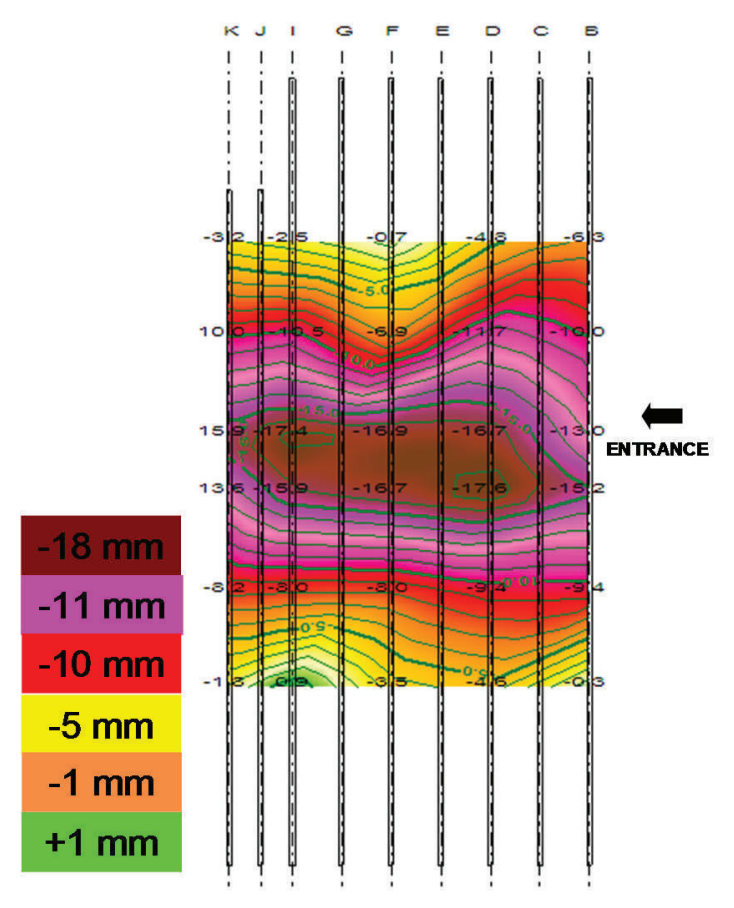

Figure 8: Isolines and hypsometry of vertical deformations

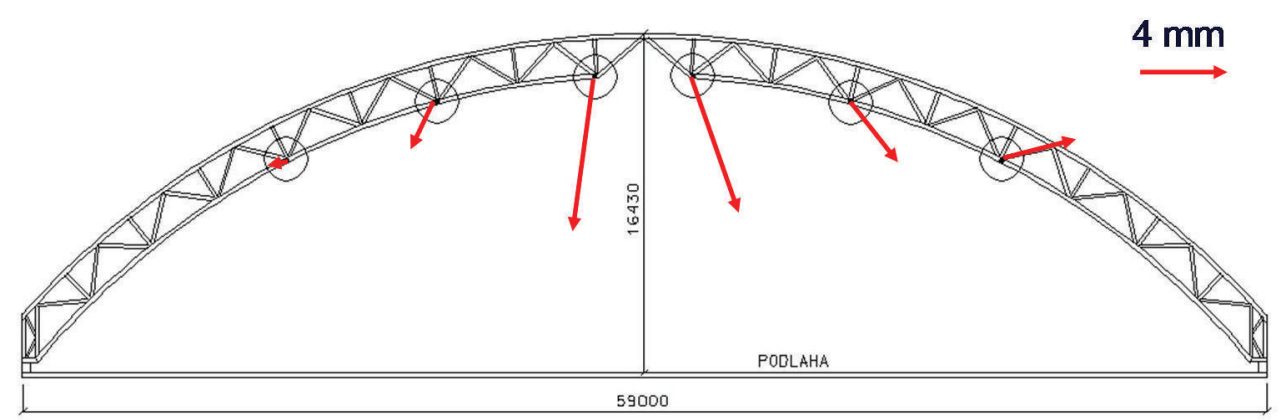

Figure 9: Mechanics of arc movements

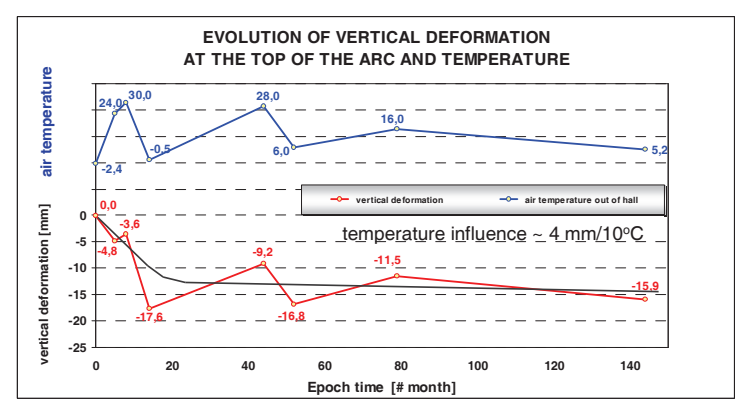

Figure 10: Vertical deformations and temperature

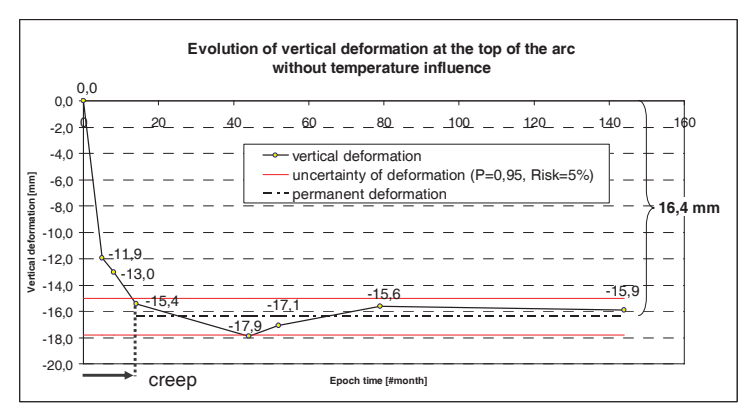

Figure 11: Vertical deformations without temperature influence 


\section{Conclusion}

The evaluation of results of geodetic measurements roof for the period 2001 to 2013 showed the effectiveness of the use of geodetic methods for monitoring the constructions of similar type. In compliance with the technology of measurement the changes and deformations greater than 1.5 $\mathrm{mm}$ can be reliably detected. Geodetic measurements showed that the actual values of deformations are small and correspond well with the theoretical deformation model in terms of the structure static model. Based on this model, for the static behavior of the structure the critical value in the transverse direction for this structure type of given span is considered $50 \mathrm{~mm}$. In the vertical direction the critical value of deformation is considered $120 \mathrm{~mm}$. At present the vertical deformation components are reaching up to $20 \mathrm{~mm}$. The construction is securely stable. The trends of variations can be assessed at this stage to infer the potentially weak points in construction, where in future we can expect the emergence of possible failures. Measured values of deformations are small and thus deep under the critical construction reliability values. The wooden roof structure during its service life is constantly in the process of aging and drying, and the result is very slow accretion of permanent deformations. The largest share of the seasonal changes in the shape of the structure have the temperature changes of the external environment the construction is "seasonally breathing". By repeated measurements further information are obtained on the structure's behavior during its operation. Knowledge learned from the measurements results are used to refine the structure static behavior model, its diagnostics and for designing of new load-bearing timber structures of similar type. Theoretical models have to be constantly verified by physical measurement, and the surveying methods for this purpose are very effective.

\section{Acknowledgements}

This paper was prepared with support of the research project AdMaS ED2.1.00/03.0097.

\section{References}

[1] STRAKA, B.: Findings from the development of new types of wood bearing systems, the contribution of the VI Conference with foreign participation - Wood in building constructions, ISBN 80-227-2138-7, STU Publishing in Bratislava, 2004 (in Czech)

[2] PEXOVÁ, J.; NOVOTNÝ, M.; ŠMAK, M.; STRAKA, B.: Construction of the pool hall in Brno - Kohoutovice, ISBN 978-80-8076-079-3, Jaga Group, Bratislava, 2009 (in Czech)

[3] BUREŠ, J., SLÁMA, J.: Measurement of deformations of steel roof truss factory building Pointworks Prostejov., Contribution to the 38th Conference Geodetic Information Days, ISBN 80-86433-13-7, Econ, Brno, 2002 (in Czech)

[4] BUREŠ, J., STRAKA, B.: Geodetic methods for measuring deformation of large span timber structures, post conference Experiment 04, ISBN 80-7204-354-4, Academic Publishing House CERM, Brno, 2004 (in Czech)

[5] HRADIL, P.; STRAKA, B.: Wooden arches with mechanical joints, the contribution of the conference Reconstruction of wooden structures and buildings, ISBN 978-80-02-02098-1, scientific society for rehabilitation and care of monuments - WTA GB , Prague, 2008 (in Czech)

[6] KALINA M.: Surveying of timber movements and deformations of large span roof structures. Master thesis. Brno University of Technology, Brno, 2010 (in Czech).

[7] KALINA, M., BUREŠ, J.: Long-term Measuring of Large Span Timber Structure of Sports Hall. 13th Professional Conference of Postgraduate Students. Brno University of technology, Academic Publishing House CERM, Brno, 2011, ISBN 978-80-214-4232-0 (in Czech). 